\title{
Corrigendum: Matrix Metalloproteinase-7 and Kidney Fibrosis
}

\section{OPEN ACCESS}

Edited and reviewed by:

Susan Yung,

University of Hong Kong, Hong Kong

*Correspondence:

Liping Yang

yangliping2018@sina.com

Xiangdong Fang

xiangdongfang818@sina.com

Specialty section:

This article was submitted to Renal and Epithelial Physiology,

a section of the journal

Frontiers in Physiology

Received: 09 March 2017

Accepted: 15 March 2017

Published: 28 March 2017

Citation:

Ke B, Fan C, Yang $L$ and Fang $X$

(2017) Corrigendum: Matrix Metalloproteinase-7 and Kidney

Fibrosis. Front. Physiol. 8:192.

doi: 10.3389/fphys.2017.00192

\section{Ben $\mathrm{Ke}^{1}$, Chuqiao Fan ${ }^{2}$, Liping Yang ${ }^{3 *}$ and Xiangdong Fang ${ }^{4 *}$}

${ }^{1}$ Department of Nephrology, The Third Hospital of Nanchang, Nanchang, China, ${ }^{2}$ Nanchang University School of Medicine, Nanchang, China, ${ }^{3}$ Department of Breast Surgery, Jiangxi Cancer Hospital, Nanchang, China, ${ }^{4}$ Department of Nephrology, The Second Affiliated Hospital to Nanchang University, Nanchang, China

Keywords: MMP-7, epithelial-mesenchymal transition, extracellular matrix, TGF- $\beta$

\section{A corrigendum on}

\section{Matrix Metalloproteinase-7 and Kidney Fibrosis}

by Ke, B., Fan, C., Yang, L., and Fang, X. (2017). Front. Physiol. 8:21. doi: 10.3389/fphys.2017.00021

In this paper titled "Matrix Metalloproteinase-7 and Kidney Fibrosis," there was a mistake in Ben Ke's department, which should be corrected. The correct work unit of Ben Ke should be Department of Nephrology, The Third Hospital of Nanchang, Nanchang, China. No other correction is needed as the text and figure legends are correct.

Conflict of Interest Statement: The authors declare that the research was conducted in the absence of any commercial or financial relationships that could be construed as a potential conflict of interest.

Copyright $\odot 2017 \mathrm{Ke}$, Fan, Yang and Fang. This is an open-access article distributed under the terms of the Creative Commons Attribution License (CC BY). The use, distribution or reproduction in other forums is permitted, provided the original author(s) or licensor are credited and that the original publication in this journal is cited, in accordance with accepted academic practice. No use, distribution or reproduction is permitted which does not comply with these terms. 